\title{
Methylmalonic Aciduria Due to Methylmalonyl-CoA Mutase Deficiency
}

National Cancer Institute

\section{Source}

National Cancer Institute. Methylmalonic Aciduria Due to Methylmalonyl-CoA Mutase Deficiency. NCI Thesaurus. Code C148366.

An autosomal recessive form of methylmalonic aciduria caused by mutation(s) in the MUT gene, encoding methylmalonyl-CoA mutase, mitochondrial. 